\title{
El origen de la revuelta judía contra Roma (66 d.C.) según el testimonio de Tito Flavio Josefo
}

\author{
The origins of the judaic revolt against Rome (66 d.C.) \\ on Flavius Josephus
}

\author{
Eduardo Pitillas SalañeR*
}

\begin{abstract}
RESUMEN
En el año 66 d.C. y como culminación a la, según Josefo, nefasta gestión de Gesio Floro, procurador romano de Judea entre los años 64 al 66 d.C., estalla una revuelta que deriva en guerra abierta contra Roma [66-74 d.C.]. Análisis de los motivos.
\end{abstract}

\section{PALABRAS CLAVE}

Procuradores romanos, zelotes y sicarios, bandidos, terrorismo urbano, asedios, legiones y tropas auxiliares.

\section{ABSTRACT}

In $66 A D$. as culmination of the, according to Josephus, Gesio Floro's dreadful management, roman procurator of Judea between 64 and $66 A D$., a revolt broke out that finished in an open war against Roma (66-74 AD.). Analysis of the motives.

\section{KEYWORDS}

Roman Procurators, Zealots and Sicarii, Bandits, Urban Terrorism, Sieges, Legions and Auxiliary Troopps.

Los siguientes párrafos de este trabajo, que tiene relación con otro anterior publicado en esta misma revista ${ }^{1}$, se centran en los motivos ${ }^{2}$ del desencadenamiento de la rebelión judía contra Roma, iniciada en el año 66 d.C. Constituye el punto de arranque de una cruenta guerra que culmina con el asedio y destrucción de Jerusalén por las tropas de Tito [70 d.C.], y se prolonga hasta el año 74 d.C. con la ocupación de las últimas fortalezas de la resistencia judía (Herodion, Maqueronte y, especialmente, Masadá).

* Dr. Historia Antigua. Camilo Alonso Vega, 48, Portal 1, $1^{\text {a }}$ A. 39005 Santander. IES Augusto González de Linares (Santander). E-mail: ug-hematología @ humv.es.

1 E. Pitillas Salañer, «La guerra de los judíos contra Roma y las luchas internas por el control de Jerusalén. Las rivalidades frente al enemigo exterior. [66-70 d.C.]», ETF, Serie II, Historia Antigua, 17-18, 2004-2005, 191-206.

2 P. Bilde, «The Causes of the Jewish War according to Josephus», JStJ, 10, 1979, 179-202. 
Puesto que no resulta posible contar con el punto de vista de Justo de Tiberíades al que Josefo califica de engañoso y poco veraz ${ }^{3}$, debemos apoyarnos exclusivamente en el relato del historiador judío prorromano $0^{4}$ a la hora de conocer los detalles referidos a los acontecimientos que condujeron a la guerra sostenida por los judíos contra Roma entre los años 66 al 74 d.C.

Si determinados aspectos referidos a la cultura material pueden conocerse a través de la arqueología, como es el caso del Templo de Jerusalén, maravilla arquitectónica de la época ${ }^{5}$, Cesarea Marítima y su importancia como puerto que abría Judea al resto del Mediterráneo ${ }^{6}$ y Masadá $^{7}$, enclave de la resistencia agónica de los sicarios, según nos cuenta el propio Josefo [Bell lud., VII, 252-

3 Tito Flavio Josefo introduce un excursus (Autobiografía, 65, 336-367) a propósito de su rival al que le acusa de haber publicado su obra tras la muerte de los emperadores [Vespasiano y Tito] y de otros testigos oculares que estuvieron presentes y fueron actores de los acontecimientos del conflicto pues «te atreves a publicarlo ahora, cuando esas personas ya no están entre nosotros y sabes que no te van a desmentir» (Autobiografía, 65, 360). El rey [Agripa II], todo según el mismo Josefo, testimonia en 62 cartas, de las que el historiador incorpora dos (Autobiografía, 65, 364-366), la autenticidad del relato que también leyeron Vespasiano y Tito y que se apoyaba en las Memorias de Vespasiano (Autobiografía, 65, 342) y de Tito (Autobiografía, 65, 358) no leídas estas últimas por Justo para el relato del asedio de Jerusalén. (F. Josefo, Autobiografía. Contra Apión, Introducción: L. García Iglesias. Traducción y notas: M. Rodríguez de Sepúlveda. Ed. Gredos. Madrid, 1994). No obstante se ha de tener en cuenta que respecto a las otras obras de Josefo [Guerra de los judíos, Antigüedades judías y contra Apión], esta última [Autobiografía] responde, en cierta medida, a una autojustificación escrita además de forma más precipitada y menos cuidada que las anteriores. De este modo se consideran menos fiables los hechos que aquí aporta como por ejemplo, entre otros, qué autoridad le designó (si los radicales o los moderados) para dirigir la guerra en Galilea, por lo que las contradicciones apreciadas entre la Autobiografía y la Guerra de los judíos, en aspectos concretos, deberían inclinarse a favor de la versión que aporta en la segunda de tales obras y no en la primera, por lo anteriormente expuesto: F. Josefo, Antigüedades judías, I, Introducción: J. Vara Donado, Madrid, 2002, 11.

${ }_{4}$ No se puede tomar al pie de la letra esta etiqueta y pensar que Josefo era un simple «agente historiográfico" del poder romano sino que, por el contrario, siempre se identificó con su pueblo, el judío. Para él el conflicto interno, la stasis (guerra civil), es tanto o más importante que la guerra mantenida contra Roma, y a la hora de repartir «culpabilidades» igualmente lo hace entre los judíos (los tiranos) como entre los magistrados romanos corruptos (los procuradores, especialmente Gesio Floro). Para estas cuestiones y otras referidas a la metodología y técnica de trabajo (el no muy ajustado «corta y pega» de determinados pasajes), vid., J. Sievers, "Flavio Josefo y su relato en la historia del Segundo Templo. Percepciones y fuentes», Conferencia dictada el 25 de junio de 2001 en la sede del Seminario Rabínico Latinamericano, Revista bíblica, 3-4, 2004, 215-235. Sobre Flavio Josefo vid., también, entre otros: R. Laqueur, Der jüdische Historiker Flavius Josephus (ein biographischer Versuch auf neuer quellenkritischer Grundlage), Giessen, 1920 (1970); H. St., Thacheray, Josephus, the man and the historian, N. York, 1929 (1967); M. Hadas-Lebel, Flavio Josefo. El judío de Roma, Barcelona, 1994; F. Sen, «Para una bibliografía crítica del estudio y ediciones de Flavio Josefo en España», Gerión, 17, 1999, 361-384.

5 Sobre el Templo en época herodiana: Th. A. Busink, Der Tempel von Jerusalem von Salomo bis Herodes, II, Leiden, 1970,1062 ss. J. Comay, The Temple of Jerusalem with the history of the Temple Mount, Londres, 1975. J.D. Crossan y J. L. Reed, Jesús desenterrado, Barcelona, 2003, 240 ss.

6 L.I. Levine, Caesarea under Roman Rule, Leiden, Brill, 1975. B. Lifshitz, Césarée de Palestine, son histoire et ses institutions, ANRW, II, 8, 1977, 490 ss.

7 Y. Yadin, Masada. La fortaleza de Herodes y el último bastión de los Zelotes, Barcelona, 1977. 
406], o servirnos de la numismática ${ }^{8}$ y la epigrafía ${ }^{9}$, lo cierto es que nada puede sustituir al relato de los acontecimientos aunque éstos deban, por fuerza, inscribirse en el contexto económico, social ${ }^{10}$, religioso -éste de importancia capitalque le es propio, especialmente teniendo en cuenta las específicas y singulares relaciones entre los judíos y Roma, no basadas siempre en la confrontación permanente, aunque no por ello exentas de tensiones y conflictos puntuales graves ${ }^{11}$.

No es correcto trazar una hipótesis de trabajo basada en la confrontación entre los judíos y Roma. De hecho, las relaciones no fueron siempre tensas ni excesivamente violentas. Por otro lado, aunque es cierto que zelotes y sicarii fueron los protagonistas de un enfrentamiento larvado, que venía de lejos y que se hizo directo y violento a partir del 66 d.C., no se ha de olvidar que otros sectores de la sociedad judía no llevaron las cosas hasta ese extremo, como es el caso de los propios fariseos ${ }^{12} y$, más aún, respecto a los sectores económicamente capacitados, rebosantes de helenismo, como ocurre con los saduceos, algunas de cuyas principales familias monopolizaron el control del sumo sacerdocio ${ }^{13}$.

Esta ambigüedad de la sociedad judía de la época hace pensar en la falta de cohesión del judaísmo, cuestión que pudo estar marcada tanto por la propia geografía dispersa del país ${ }^{14}$, como por la trayectoria histórica de reciente expansión del núcleo étnico-religioso judío sobre sus confines inmediatos (Galilea, Perea, Idumea) y, finalmente, por la inveterada disfunción religiosa respecto a los samaritanos.

Por todo ello, no resulta posible, como ocurre en toda estructura social propia de la Antigüedad (dados los lazos interpersonales y de fidelidad clientelar), hablar genéricamente de judíos a la hora de enfocar un conflicto de tal naturaleza, que exige, en cada uno de sus grupos y miembros, una determinada postura difícilmente unívoca frente a Roma y su Imperio.

A la guerra contra Roma se llega como resultado de un clima de progresivo enrarecimiento en el marco de una situación social y económica determinada, bajo la presión de un mesianismo apocalíptico y liberador, y fruto también del propio desencuentro de la sociedad judía, profundamente dividida desde época asmonea.

8 Catalogue of the Greck Coins of Palestine (Galilee, Samaria and Judaea), George Francis Hill M.A., Arnaldo Forni Ed., 1914, 220-316 y láminas, XXII-XXXVIII [monedas a partir de Herodes el Grande...]. K. Kadman, The coins ot the Jewish War of 66-73, Jerusalén, 1960.

9 Corpvs Inscriptionvm Ivdaicarvm. Recueil des inscriptions juives qui vont du III siècle avant JèsusChrist au VII siècle de notre ère, II, Roma 1952.

$10 \mathrm{~J}$. Juster, Les juifs dans l'empire romain, leur condition juridique économique et sociale, I-II, París, 1914 (reimp., N. York, 1963). M. Sartre, El Oriente Romano. Provincias y sociedades provinciales del mediterráneo oriental, de Augusto a los Severos (31 a.C.-235 d.C.), Madrid, 1994, 383 ss.

${ }_{11}$ M. Hadas-Lebel, «L'évolution de l'image de Rome auprès des Juifs en deux siècles de relations judéo-romaines, -164 á +70", ANRWII, 20.2, 1987, 715-856.

12 E. Schürer, Historia del pueblo judío en tiempos de Jesús 175 a.C.-135 d.C., edición dirigida y revisada por G. Veermes, F. Millar y M. Black, I, Madrid, 1985, 507 ss.

13 Id., Ibídem, II, 271 ss.

14 M. Noth, Historia de Israel, Barcelona, 1966, 13-30. 
De hecho, el panorama de enfrentamiento civil es constante en un momento en el que Judea se ha liberado de la tutela egipcia de los Ptolomeos para - precariamente- pasar a la seléucida de Syria. Y es en esa época cuando apuntan determinados deseos de liberación pero también - y de forma peligrosa- se vislumbra la división interna entre los propios judíos ${ }^{15}$. El decreto de Antioco IV Epifanes introduciendo medidas que ponían en peligro costumbres profundamente arraigadas entre los judíos como la circuncisión [I Macabeos, 1, 43-52], tuvo que contar con el apoyo de sectores judíos helenizados lo que provocó la ira de Matatías (166 a.C.) en Modín (el-Midya), [l Macabeos, 2, 24] ${ }^{16}$. La reacción macabea supuso un frenazo a esas pretensiones progresistas posiblemente muy poco respetuosas con el sentimiento religioso tradicional. No deja de resultar curioso el hecho de que tal medida difícilmente la hubiera intentado el emperador Adriano, aunque frecuentemente se ha argumentado tal motivo para la revuelta de Bar Kokhba ${ }^{17}$. Entre esas tensiones, la defensa a ultranza de los ritos y cultos de la sociedad hebraica y la progresiva influencia helénica, siempre displicente con la pureza ritual judía, y con el peligro añadido de la inquietante difusión del politeísmo y la presencia in crescendo de gentiles entre los judíos (para quienes Herodes el Grande [37-4 a.C.] manda construir el conocido pórtico aunque no se les permita pasar a otros escenarios sacros del Templo reservado para mujeres, varones y sacerdotes judíos), se debaten los diferentes sectores del judaísmo. Por ello, tanto desde el punto de vista religioso como del cultural y político, difícilmente resulta posible hablar de unidad. De hecho, las querellas dinásticas por el control del trono hace que Pompeyo ${ }^{18}$ intervenga en los asuntos judíos como respuesta no sólo a los propios intereses geopolíticos de Roma en la zona, sino que son los mismos judíos los que acuden directamente a la autoridad romana, reclamando intervenga en favor de una u otra facción, la de Aristóbulo (y sus hijos) o la de Hircano ${ }^{19}$.

La guerra contra Roma no es sólo un conflicto de tipo colonial contra el imperio de la época, tal y como pudiera ser visto desde una perspectiva contemporánea y - salvadas todas las distancias que separan dos mil años de existencia-, sino que también es un conflicto social (de clases en la terminología marxista) entre los

15 Las rivalidades y odios afloran con fuerza durante el reinado de Alejandro Janeo (103-76 a.C.): P. Sacchi, Historia del judaismo en la época del Segundo Templo. Israel entre los siglos VI a.C. y I d.C., Madrid, 2004, 280 ss.

16 M. Noth, Historia de Israel, Barcelona, 1966, 327-328.

17 La prohibición de la circuncisión [Esparciano, SHA (Vita Hadriani), XIV, 2], práctica mutilatoria poco acorde con la cultura helenístico-romana, no parece que afectara directamente a los judíos sino que pudo tratarse de una medida que buscara limitar exclusivamente esta práctica dentro del ámbito del proselitismo, impidiendo así una difusión non grata: B. Isaac, «La política religiosa de Adriano y la segunda revuelta judía», en J. M. Cortés Copete y E. Muñoz Grijalvo (Eds.), Adriano Avgvsto, Sevilla, 2004, 151.

18 L. Amela Valverde, Cneo Pompeyo Magno. El defensor de la República Romana, Madrid, 2003.

19 M. Noth, Historia de Israel, 359 ss. Tanto los partidarios de Aristóbulo como los de Hircano acudieron a Escauro, delegado de Pompeyo, para terciar sobre el apoyo romano a uno de los dos, y aunque Escauro decide apoyar a Aristóbulo, asediado en Jerusalén por Aretas rey de los nabateos que apoya a su rival Hircano, posteriormente Pompeyo, tras reflexionar seriamente sobre el asunto, decide inclinarse por Hircano impresionado quizá por el apoyo que este último recibe de los notables judíos (F.J., Ant., XIV, 43), más de 1000 que acuden al campamento de Pompeyo, "versión israelita de los equites romanos" como apunta P. Sacchi, Historia del judaísmo en la época del Segundo Templo, Israel entre los siglos VI a.C. y I d.C., Madrid, 2004, 289. 
sectores más radicalizados (zelotes) y los notables, cuya inclinación a Roma es, por su posición más desahogada, evidente (pero no en todos los casos y en todas las circunstancias). Y este conflicto -entre grupos sociales rivales- es algo que se lee constantemente en Flavio Josefo aunque este último, por su origen familiar y su formación, esté próximo a los notables y pudiera haber pertenecido al sector fariseo ${ }^{20}$. Esa brutal guerra social (que se registra en Jerusalén durante todo el asedio) únicamente se detiene ante la presencia de las poderosas tropas de Tito, quienes comienzan a asediar la capital judía en la primavera del 70 d.C.

La revuelta del 66 d.C. pudo sorprender o desbordar a los notables, especialmente al grupo sacerdotal, que hizo lo imposible por encauzar las tensiones y frenar la peligrosa desvinculación con Roma, patente en el momento en el que Eleazar, hijo del sumo sacerdote Ananías ${ }^{21}$, decide suspender el sacrificio diario en honor al emperador, uno de los motivos principales (y simbólicamente más graves) de ruptura con Roma ${ }^{22}$. El propio Josefo posiblemente se viera forzado a abrazar una secesión en la que no creía demasiado y, finalmente y sin excesiva ilusión, catapultado a coordinar las fuerzas judías en Galilea ${ }^{23}$, ante la inminente presencia romana en el área.

Como es conocido Josefo, tras estar al frente durante cuarenta y siete días en el asedio de Jotapata, se entrega a Vespasiano a quien la fortuna le acompaña en su predicción como futuro purpurado ${ }^{24}$. A partir de este momento deja de ser un notable-resistente poco convencido para a ser, cada vez más, un judío-romano antizelote, impregnado de cultura helenística y, no por ello, obligado a renunciar al judaísmo (pues ni Roma ni sus nuevos patronos le fuerzan a ello y tras su obra sobre la Guerra de los judíos no precisa escribir sus Antigüedades Judías por aplacar su mala conciencia).

Pero, ¿hasta qué punto podemos fiarnos del relato de Flavio Josefo? ¿No se trata de una fuente sesgada y parcial? ¿No está justificando a Roma, a Vespasiano y a Tito, sus patronos y patrocinadores?

Tito Flavio Josefo escribió, tras la guerra, una obra que pretendía convencer al público helenizado (judíos y partos) de lo innecesario de un conflicto que había provocado la ruina y aniquilación de la comunidad judía de su época con las nefastas consecuencias conocidas: desaparición de la figura del Sumo Sacerdote, del Gran

20 F.J., Autobiografía, 2, 12.

21 Ananías, hijo de Nedebeo, segundo de los sumos sacerdotes (tras José, hijo de Camey o Camido) nombrado por Herodes de Calcis (44-48 d.C.), impopular por su avaricia y asesinado por los insurrectos [F.J., Bell lud., II, 429 y 441].

${ }_{22}$ F.J., Bell lud., II, 409-410.

23 Vid., no obstante, n. 1.

${ }^{24}$ S. Perea Yébenes, «Tito César: las vísperas de la púrpura», S. Perea Yébenes (ed.), Res Gestae -grandes generales romanos-(I), Madrid, 2004, 157-209. 
Sanedrín, destrucción del Templo y de Jerusalén, capital de Judea, por las tropas de Tito, futuro purpurado. Todo ello tuvo que pesar en el ánimo de Josefo por lo que no ahorra cifras (no libres de exageración) a la hora de cuantificar las masacres llevadas a cabo tanto por los propios romanos como por sus compatriotas exaltados.

Se ha de distinguir, por lo tanto, entre los hechos, que expone desde una perspectiva romana ${ }^{25}$ y su posición personal en el conflicto que también manifies$\mathrm{ta}^{26}$. Josefo interpreta que los sumos sacerdotes y notables no pudieron encauzar el conflicto y se vieron desbordados por los elementos más radicales, los tiranos ${ }^{27}$ (zelotes y sicarii). A ellos hace responsables de la situación que se vive en el interior de Jerusalén, escenario de un brutal enfrentamiento civil. Su posición en este aspecto es bien clara, por lo que no ahorra detalles a la hora de identificar bandidaje y radicalismo político, cuestión, por otro lado, difícil de separar en un contexto de paulatino deterioro social y económico.

Aunque las cifras de víctimas que aporta Josefo estén a todas luces hinchadas, ya que no coinciden grosso modo con los datos de la población de Palestina ${ }^{28}$, el historiador judío presta su atención en los miembros de la resistencia ${ }^{29}$, incluso más que en los romanos, aunque en estos últimos tiene más en cuenta las acciones heroicas individuales ${ }^{30}$, no ahorrando detalles al respecto.

El proceder de Tito, su héroe, es en todo momento mesurado. Aquí transmite un mensaje políticamente correcto. Tito, en consejo de guerra en el que recaba la opinión de sus generales, decide no destruir el Templo, aunque sobre esta cuestión la historiografía actual no es unánime respecto a la responsabilidad del estratega romano ${ }^{31}$. Para Josefo, el proceder impío e irracional de los sitiados en Jerusalén no hace sino provocar el abandono de Dios, lo que explica que éste esté de parte de los romanos y que, por consiguiente, permita la destrucción del Templo.

El ejército romano era además una maquinaria disciplinada, profesional y digna de elogio como lo manifiesta en su conocido excursus ${ }^{32}$, lo que no le impide observar brutales matanzas de población civil, en momentos del asalto a enclaves que habían aguantado, con tenacidad y fanatismo el asedio, como ocurre en los

${ }^{25}$ La aparente insensibilidad de Tito Flavio Josefo hacia sus compatriotas se explicaría en todo caso por apreciar los hechos desde un punto de vista romano: M.Hadas-Lebel, «L'évolution de l'image de Rome...», 820.

${ }^{26}$ Vid., F. Josefo, La Guerra de los judíos, Proemio, 1-30. Traducción: J. M. ${ }^{a}$ Nieto Ibáñez, Ed. Gredos, Madrid, 1997.

27 Vid., supra nota 4.

28 En torno a algo menos de 100.000 habitantes para la capital, Jerusalén y 2.000 .000 para toda Palestina: M. Broshi, «La population de l'ancien Jérusalem», Revue Biblique, 82, 1975, 5-14. J. Beloch, Die Bevölkerung der Griechisch-Roömischen Welt, Roma, 1968, 247 y ss.

${ }^{29}$ F.J. Bell lud., V, 248-251; V, 474; VI, 92 y VI, 148.

${ }^{30}$ Como ocurre, por ejemplo, con los casos del soldado sirio Sabino, del centurión Juliano y del jinete Pedanio: F.J. Bell lud., VI, 54-67; VI, 81-91;VI, 161-163.

${ }^{31}$ E. Schürer, Historia del pueblo judío en tiempos de Jesús..., II, n. 115, 244-245. M.Hadas-Lebel, «L'évolution de l'image de Rome...», 825. B. Lifshitz, «Jérusalem sous la domination romaine. Histoire de la ville despuis la conquête de Pompée jusqu'à Constantin (63 a.C.-325 d.C.), ANRW II, 8, 467-468.

${ }^{32}$ F.J. Bell lud., III, 70-109. 
casos descritos de Jotapata ${ }^{33}$, Gamala ${ }^{34}$ y de Jerusalén ${ }^{35}$. Este comportamiento, no obstante, era habitual en todos los ejércitos del mundo antiguo. Del lado romano existe un ejército profesional y disciplinado, integrado por legiones, cuerpos auxiliares $^{36}$ y aliados clientes, bien armado, pertrechado y alimentado. De la parte judía una milicia civil e improvisada, que suple su falta de preparación con el arrojo y la temeridad propia de la desesperación.

Pero aunque los judíos luchaban bajo tales condiciones (o precisamente por ello) no podían hacer frente a los ejércitos romanos en campo abierto, por lo que la resistencia se centró en ciudades y aldeas donde los sicarii habían adquirido experiencia en acciones de terrorismo urbano. El asedio de Jerusalén (durante la primavera-verano del 70 d.C.) [F.J. Bell lud., V y VI], en el que participaron cuatro legiones romanas [V Macedonica, X Fretensis, XII Fulminata y XV Apollinaris] y tropas auxiliares, bajo el mando de Tito, hasta un total de unos 65.000 hombres $^{37}$, muestran a las claras la dureza de aquella guerra en un medio como el urbano (siempre temido por los ejércitos de ayer y de hoy).

Pero que Josefo descargue buena parte de la responsabilidad sobre los integrantes de la cuarta filosofía (zelotes) no quiere decir que la autoridad romana estuviera exenta de ella, como bien pudo observarse en años anteriores con algunas de las provocaciones del prefecto Poncio Pilato ${ }^{38}$.

Tras la muerte de Agripa I (44 d.C.) ${ }^{39}$, entre los procuradores que se sucedieron en los años 44 al 66 d.C., aunque no en todos los casos, se fue generando un clima de tensión, mantenido por los propios zelotes y sicarii y alentado, en todo caso, por la corrupción de los magistrados romanos como ocurre, especialmente, bajo Cumano (48-circa 52 d.C.), y posteriormente con el liberto Félix (52-60 d.C.), situación que se torna prácticamente irreversible con Luceyo Albino (62-64 d.C.) y Gesio Floro (a partir del 64 d.C.).

${ }^{33}$ F.J. Bell lud., III, 141-288 y 316-339.

34 F.J. Bell lud., IV, 11-53 y 62-83.

35 F.J. Bell lud., V y VI.

${ }^{36}$ Gonzalo G. Queipo, «Aproximación al vocabulario militar de Flavio Josefo, $\delta \varepsilon \kappa \alpha \delta \alpha ́ \chi \eta \varsigma$ y $\tau \alpha \xi ı \alpha \chi \chi \varsigma$ en el Bellum ludaicum», Aquila Legionis, 10, 2008, 39 y ss.

37 B. Lifshitz, «Jérusalem sous la domination romaine...», ANRW II, 8, 468.

${ }_{38}$ Como ocurre, por ejemplo, con el asunto de los estandartes que provoca una marcha judía multitudinaria sobre Cesarea Marítima [C.H. Kraeling, «The Episode of the Roman Standarts at Jeruralem», HThR, 35, 1942, 263-289], como cuando pretende construir un acueducto en Jerusalén utilizando fondos del Templo o sitúa escudos votivos — sin imágenes - con el nombre del emperador (Tiberio) en el praetorium. El emperador ordena retirarlos y depositarlos en el templo de Augusto en Cesarea Marítima al darse cuenta de que se trata de una postura desafiante del prefecto [P.L. Maier, «The Episode of the Golden Shields at Jerusalem», HThR, 62, 1969, 109-121].

${ }_{39}$ Marco Junio Agripa tuvo una vida novelesca y pocos hubieran pensado que llegaría a ser rey de los judíos y que heredaría la mayor parte de las posesiones de su abuelo Herodes el Grande. Su alocada y turbulenta vida, perseguido en sus comienzos por los acreedores, concluye de modo digno sentándose en el trono de Judea (37-44 d.C.), gobernando moderadamente y siendo, en todo momento, respetuoso con las tradiciones judías. Al propio Flavio Josefo no deja de sorprenderle semejante transformación, resultado quizá del destino o del azar. 
A este último, Gessius Florus ${ }^{40}$ Josefo atribuye una buena parte de la responsabilidad, como veremos, en el desencadenamiento del conflicto. Da la impresión de que en Josefo se apunta la conjunción de dos factores: por un lado el radicalismo zelote, mantenido y alentado a partir del rechazo al censo confeccionado en época de Quirino ${ }^{41} \mathrm{y}$, por otro, la acumulación corrupta de procuradores que alcanza su climax con el último de ellos, Gesio Floro ${ }^{42}$.

Josefo hace alusiones constantes a un tipo de procurador nefasto, inculpándolo gravemente en el desencadenamiento de una crisis irreversible que, en buena medida, parece buscada a propósito por él mismo. De Gesio Floro — destaca Josefoque si el procurador Albino, su predecesor en el cargo, era un corrupto por sus frecuentes robos y extorsiones [F.J., Bell lud., II, 272-276], Floro lo fue aún peor, pues ya no guardó disimulo alguno y todo lo hacía descarada y cruelmente ${ }^{43} \mathrm{y}$, lo que era aún más grave, "planeaba la guerra», buscando de forma consciente la sublevación, para tapar y desviar sus iniquidades ante su máximo superior, el emperador [F.J., Bell lud., II, 282-283]. Buscando «encender la guerra» ordena extraer diecisiete talentos del tesoro de Templo [F.J. Bell Iud., II, 293-294] y al estallar el conflicto, siempre latente entre la población greco-siria y judía de Cesarea Marítima, —para Josefo uno de los detonantes que lleva al «comienzo de la guerra»- [F.J. Bell lud., II, 284], no parece que el procurador haga nada para encauzar el problema, sino todo lo contrario [F.J. Bell lud., II, 287-288]. Se comporta de un modo abusivo in-

40 Vid., el término: Gessius Florus (170) en Prosopographia Imperii Romani, IV, 1, Berlín, 1952, 32.

41 E. Schürer, Historia del pueblo judío en tiempos de Jesús...., I, 515-550.

42 «Lo dicho acerca de los Sumos Sacerdotes es suficiente. Por su parte, Gesio Floro, quien fue enviado por Nerón como sucesor de Albino, llenó Judea de calamidades de todo tipo. Era éste oriundo de Clazómenas y llevó consigo a Judea a su esposa Cleopatra, gracias a cuya amistad con Popea, la mujer de Nerón, del que ella no se diferenciaba lo más mínimo en perversidad, obtuvo el gobierno de esta provincia. Fue en el ejercicio del poder tan malvado y violento que por el cúmulo de sus fechorías los judíos elogiaban a Albino y lo consideraban su bienhechor. En efecto, mientras aquel trataba de mantener oculta su perversidad y procuraba cuidar de que no se le descubriera en forma alguna, Gesio Floro, en cambio, como si hubiera sido enviado a Judea para hacer ostentación de perversidad, alardeaba de los desafueros cometidos contera nuestro pueblo, no excluyendo forma alguna de rapiña ni de suplicio inicuo. Era, en efecto, insensible a la compasión, insaciable en cualquier ganancia, hasta el punto de que para él no sólo los más pingües no se diferenciaban lo más mínimo de los más insignificantes, sino que incluso se asoció a los bandoleros, puesto que eran muchos los que se dedicaba a este menester, con total impunidad, ya que estaban seguros de tener garantizada por él la vida a cambio de compartir botín. Estos robos no eran módicos, sino que los infelices judíos, al no poder soportar los continuos saqueos perpetrados por los bandoleros, se vieron obligados a abandonar sus lugares de residencia y a huir en masa en la idea de que vivirían mejor en cualquier parte del extranjero. ¿Y qué falta hace relatar más hechos de él? En efecto, él fue quien nos obligó a emprender la guerra contra los romanos, porque partíamos de la base de que era preferible perecer de una vez que poco a poco. $Y$, efectivamente, la guerra empezó al segundo año de ser nombrado procurador Floro y al duodécimo de ser designado Nerón emperador» [F.J. Ant., XX, 252-257. Traducción: J. Vara Donado]

43 «Albino realizaba sus perversidades a escondidas y con disimulo, mientras que Gesio se vanagloriaba públicamente de sus ilegalidades contra el pueblo y...realizó todo tipo de rapiñas y de agravios. Era una persona muy cruel en situaciones que eran dignas de piedad, y no mostraba ningún pudor en cometer acciones vergonzosas...saqueó a ciudades enteras y arruinó a pueblos enteros. Poco faltó para proclamar públicamente por todo el país que estaba permitido dedicarse al bandidaje, con la condición de

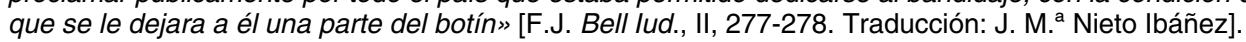


citando a la población judía en la capital, Jerusalén, al frente de una cohorte de infantería y de un destacamento de caballería [F.J. Bell lud., II, 295-296], provocando una masacre (¿3.600 muertos?) [F.J., Bell lud., II, 307] y haciendo que la tropa romana actúe «con una crueldad hasta entonces desconocida» [F.J. Bell lud., II, 308].

No contento con ello, mientras sacerdotes y notables se esfuerzan por encaminar una situación que se torna cada vez más difícil y se inclina peligrosamente hacia la revuelta abierta y, además, lleva camino de desbordarse alentada por los más radicales, Gesio Floro «intentó reavivarla de nuevo» [F.J. Bell lud., 318]. Así pues, las dos cohortes que desde Cesarea Marítima se presentan en Jerusalén fueron enviadas con el objetivo de incitar a la población, no correspondiendo al saludo de sus gentes, provocando y atacando a la multitud ${ }^{44}$.

Cuando Eleazar, hijo del sumo sacerdote Ananías, como ya se mencionó supra, decide suspender el sacrificio diario en honor al emperador se inicia un proceso de no retorno y éste fue, para Josefo, «el comienzo de la guerra contra los romanos» [F.J. Bell lud., 409-410].

El procurador romano en una carta a Cestio, su superior jerárquico y, a la sazón, gobernador de Syria por aquel entonces [F.J. Bell Iud., II, 333], echa la culpa de todo lo acontecido en Jerusalén, a los judíos. Cestio se muestra falto de firmeza ante el procurador, autentico responsable de todo lo que ocurre, y no parece que en esto deba dudarse del testimonio de Josefo ${ }^{45}$.

Los notables judíos, hacia los que Josefo se siente políticamente cercano, se ven desbordados por los radicales (zelotes) y solicitan la ayuda tanto de Floro

44 «Floro no estaba contento con que se calmara la revuelta por lo que intentó reavivarla de nuevo. Llamó a los sumos sacerdotes y a los nobles y les dijo que la única prueba de que el pueblo no se iba a sublevar ya más era que acudieran al encuentro de las tropas que venían de Cesarea. Dos eran las cohortes que acudían desde allí. Mientras los sumos sacerdotes y los notables convocaban al pueblo, el procurador envió a decir a los centuriones de las cohortes que prohibieran a sus hombres devolver el saludo a los judíos y, en el caso de que dijeran algo contra él, que utilizaran sus armas. Los sumos sacerdotes congregaron a la muchedumbre en el Templo y le rogaron que saliera al encuentro de los romanos y recibiera a las cohortes, antes de que ocurriera un desastre irreparable. Los rebeldes no hicieron caso a estas palabras y la multitud, a causa de los que habían muerto, se puso del lado de los más revolucionarios. Entonces, todos los sacerdotes y todos los servidores de Dios sacaron en procesión los objetos sagrados...se pusieron de rodillas y suplicaron al pueblo que preservase los ornamentos sagrados y que no provocase a los romanos a saquear los Tesoros de Dios...Llamaban por su nombre a cada uno de los nobles y al pueblo, de forma colectiva, y les pedían que tuvieran cuidado con no cometer ninguna pequeña ofensa que permitiera entregar la patria a unas personas que deseaban devastarla...En cambio, si ellos, como es costumbre, recibían a los soldados, quitarían a Floro el pretexto de la guerra, salvarían la patria y evitarían más sufrimientos. Además, supondría una terrible debilidad el hecho de hacer caso a un pequeño grupo de sediciosos, cuando es necesario que un pueblo tan numeroso obligue a estas personas a comportarse bien. Con estas palabras amansaron a la muchedumbre y también calmaron a los sediciosos, a unos con amenazas y a otros por el respeto que ellos merecían. A continuación, en calma y en orden, se pusieron al frente de la multitud y salieron al encuentro de los soldados; al llegar cerca de ellos les saludaron. Pero, como las tropas no les contestaran, el grupo de rebeldes empezó a gritos contra Floro. Esta era la señal que habían recibido los romanos para atacar a los judíos...» [F.J. Bell lud., II, 318-325. Traducción: J. M. ${ }^{a}$ Nieto Ibáñez].

45 «ll n'y a pas lieu non plus de croire que Josèphe a exagéré la responsabilité de Florus pour couvrir quelque faute des Juifs alor qu'il est généralment d'une impitoyable sévérité pour les siens": M. Hadas-Lebel, «L'évolution de l'image de Rome...», 808. 
como de Agripa (II) para que acudan a Jerusalén. El monarca judío [vid., anexo] presta su apoyo (aunque también se verá desbordado ya que no podrá hacerse con el control de la situación, tras el fracaso de su discurso [F.J. Bell lud., II, 345-404).

Floro, por su parte, no hace nada y Josefo interpreta que para él fue «una estupenda noticia y, como quería que estallara la guerra, no dio ninguna respuesta a los embajadores» [F.J. Bell lud., II, 420-421 ] dejando así que los acontecimientos siguieran la peligrosa pendiente del desorden y la violencia. Así, cuando se desata abiertamente esta última en Cesarea, entre ambas comunidades (siria y judía), Gesio Floro captura, de entre los judíos, a los que huyen y los lleva encadenados a los astilleros [F.J. Bell lud., II, 457]. Se desatan también los odios en otras ciudades $^{46}$ donde habitan sirios y judíos [F.J. Bell lud., II, 458-460], verdadero anticipo de la abierta rebelión posterior.

Las tropas enviadas por Agripa (I) a Jerusalén, un amplio destacamento de unos 2.000 jinetes, sólo permite a los notables hacerse con el control de una parte limitada de la ciudad (la zona alta), mientras los rebeldes, Eleazar a la cabeza, se hacen con la zona baja y el Templo, y durante siete días se prolonga la matanza entre grupos de combatientes. Además, con la ayuda de los sicarii, los rebeldes van desbordando a las fuerzas del rey, que se tienen que replegar a la Ciudad Alta [F.J. Bell Iud. II, 424-425], y, posteriormente, prenden fuego a la casa del sumo sacerdote Ananías, al palacio de Agripa y Berenice ${ }^{47}$, a los archivos (edificio que contenía documentación relativa a contratos y préstamos) y, por último, asaltan la Torre Antonia, sucesos que acontecen aproximadamente a mediados del mes de agosto ${ }^{48}$.

Las rivalidades entre los rebeldes ${ }^{49}$ se patentizan en el enfrentamiento entre los partidarios de Eleazar y los de Manahem, hijo de Judas el Galileo ${ }^{50}$. Este último se había apoderado de la fortaleza de Masadá y de las armas depositadas allí en época de Herodes. Acude a Jerusalén y a comienzos de septiembre prosigue con el asedio a la tropa romana, pero tras la ejecución de sumo sacerdote Ananías [F.J. Bell lud., II, 441], los seguidores de Eleazar, aprovechan que Manahem sube al Templo a rezar, para proceder a su captura, torturarlo y matarlo [F.J. Bell lud. II, 444-448] ${ }^{51}$. Finalmente los partidarios de Eleazar acaban totalmente con la guarnición romana

${ }^{46}$ En Filadelfia, Hesbón, Gerasa*, Pela, Escitópolis**, Gadara, Hipo, la Gaulanítide, Cadasa, Ptolemaida, Gaba y Cesarea (de Filipo, seguramente) [F.J. Bell lud., II 458-460]. En Gerasa*, sin embargo, Josefo señala, más adelante [Bell lud., II, 480], al igual que en otras ciudades como Antioquía, Sidón y Apamea, que no se produjeron ataques sobre la población judía lo que parece contradecir la violencia de ésta sobre los no judíos (?). En Escitópolis ${ }^{\star \star}$ los hebreos no apoyan a los judíos, combaten con sus compatriotas si bien al final son traicionados pues los habitantes «...de Escitópolis temían que los judíos tomaran de noche la ciudad y justificaran su defección ante sus hermanos de raza con una gran matanza entre sus habitantes» [F.J., Bell lud., II, 467. Traducción: J. M. ${ }^{2}$ Nieto Ibáñez].

47 S. Perea Yébenes, Berenice. Reina y concubina, Madrid, 2000.

48 Del 14 a 16 de Loos, calendario macedónico, tendrían lugar estos acontecimientos con el ataque a la Torre Antonia la captura y ejecución de sus soldados [F.J. Bell lud., II, 430].

49 E. Pitillas Salañer, «La guerra de los judíos contra Roma y las luchas internas por el control de Jerusalén. Las rivalidades frente al enemigo exterior. [66-70 d.C.]», ETF, Serie II, Historia Antigua, 17-18, 2004-2005, 191-206.

50 F.J., Ant., XVIII, 1-10.

51 Se salva de la matanza Eleazar, hijo de Jairo, de la familia de Manahem, jefe de los sicarii que resistirá en Masadá el asedio de Flavio Silva [F.J. Bell lud., VII, 252-406]. 
tras una falsa promesa de capitulación que no cumplen ${ }^{52}$. En Maqueronte la guarnición romana acuerda entregar la fortaleza a otra judía [F.J. Bell lud., II, 486].

La situación era ya tan grave (Jerusalén en manos de los rebeldes) que se hacía necesaria la intervención directa del gobernador de Syria C. Cestius Gallus quien reúne una fuerza cuantificada entre 17.000 y 20.000 hombres $^{53}$ quien, al fracasar también, dio paso a las campañas de Vespasiano y Tito (años 67 al 70 d.C.), futuros emperadores.

Los acontecimientos fueron del siguiente modo.

Las tropas de Cestio se dedican al pillaje en Galilea, asedian por mar y tierra Jope y su caballería efectúa razias en la toparquía de Narbatene, ataques que no impiden a los judíos, a su vez, hostigar a grupos de romanos rezagados provocándoles bajas [F.J. Bell lud., II, 504-509]. A. Caesennius Gallus, legado de la legio XII Fulminata, entra en Séforis, ciudad aliada de Roma, entre aclamaciones.

Cestio Galo en su desplazamiento hacia Jerusalén recorre Antípatris [act. Tell Ras el-Áin], Lida y acampa en Gabaón a 50 estadios $^{54}$ de Jerusalén donde sufre ataques por parte de los judíos [F.J. Bell lud., II, 519-520]. Simón Bar Giora, «hijo del prosélito» (posteriormente famoso lider zelote en Jerusalén: F.J. Bell lud., IV, 503-508; D. Cass., LXVI, 7, 1; Tac., Hist., V, 12) es uno de los cabecillas que ataca a los romanos ${ }^{55}$. Finalmente Cestio Galo acampa en Escopo [Safein, skopós = atalaya, observatorio] (donde posteriormente también lo harán las legiones de Tito, la XII Fulminata y la XV Apollinaris en la primavera del 70 d.C.), a siete estadios de la capital (a algo más de $1 \mathrm{~km}$. de distancia). La indecisión del jefe romano unida a la corrupción de los mandos ${ }^{56}$ y al hecho de que decidiera abandonar el asedio al sexto día de iniciado, no hizo sino animar a los judíos a atacar a la tropa

52 «La gente se puso a hacer manifestaciones de duelo públicamente, al ver que ya había motivos insalvables para ir la guerra y que la ciudad estaba manchada por un crimen tan grande que hacía esperar lógicamente un castigo divino, aunque no se tratara de la venganza de los romanos. La ciudad se llenó de tristeza y todas las personas moderadas estaban inquietas ante el hecho de que ellas fueran castigadas por culpa de los rebeldes. Pues la matanza había tenido lugar en sábado, día en el que los judíos, por su religión, no realizan ningún trabajo, ni siquiera las labores normales» [F.J. Bell lud., II, 455456. Traducción: J. M. ${ }^{a}$ Nieto lbáñez.]

53 Las tropas que el gobernador de Syria reunió fueron la legio XII Fulminata (procedente de Antioquía), vexillationes (unos 2.000 hombres) procedentes de las legiones $X$ Fretensis y, seguramente, de la VI Ferrata, junto a tropas aliadas (2.000 jinetes de Antioco IV de Comagene, en torno a 2.000 jinetes de Agripa (II) y 3.000 infantes aportados también por el rey judío, 4.000 [la mayor parte arqueros y 1/3 de jinetes] de Soemo, rey de Emesa, junto a otros 3.000 arqueros y un número indeterminado de auxiliares reclutados en las ciudades fieles a Roma [F.J. Bell lud., II, 500-502].

54 Seis estadios equivalen a $1 \mathrm{~km}$. aproximadamente.

55 «...en el momento en que los romanos subían a Betoron, les atacó por detrás, desbarató la mayor parte de su retaguardia, cogió muchas de sus mulas de carga y se las llevó a la ciudad» [F.J. Bell lud., II, 521. Traducción: J. M. ${ }^{a}$ Nieto lbáñez].

56 «Si en este preciso momento hubiera querido forzar la entrada a través de las murallas, se habría apoderado inmediatamente de la ciudad y habría tenido lugar el fin de la guerra. Sin embargo, el prefecto del campamento, Tiranio Prisco, y la mayoría de los comandantes de caballería, subordinados por el dinero de Floro, le hicieron desistir de este propósito. Este fue el motivo por el que la guerra se alargó durante tanto tiempo y por el que los judíos se vieron desbordados por desgracias irreparables» [F.J. Bell lud., II, 531-532. Traducción: J. M. ${ }^{a}$ Nieto lbáñez]. 
romana, provocándole, en su retirada, un fuerte y considerable desgaste, viéndose obligada además a abandonar la mayoría de sus bagajes en el recorrido hacia Gabaón, su anterior campamento [F.J. Bell lud., II, 544]. Pero el desastre mayor se produce en la huida hacia Beth Horon y en el paso por los desfiladeros (de Beth Horon Superior a Beth Horon Inferior) teniendo que abandonar los romanos buena parte de sus máquinas de asedio ${ }^{57}$.

Las pérdidas romanas en esta retirada fueron importantes (5.300 soldados de infantería y 480 de caballería) [F.J. Bell lud., II, 555] ${ }^{58}$. Este grave contratiempo (Beth Horon) pudo haber tenido lugar el 25 de noviembre del 66 d.C. ${ }^{59}$ La legio XII Fulminata perdió además su emblema, el águila, y aunque no fue disuelta (debido a la valentía de 400 de sus hombres que cubrieron la retirada), sí sufrió un importante desprestigio ${ }^{60}$, del que intentó resarcirse posteriormente cuando fue incorporada al ejército de Tito con vistas al asedio de Jerusalén en el 70 d.C.

En resumen, todos los hechos señalados por Tito Flavio Josefo (fuente principal y única para tales sucesos) nos sitúan ante el estallido de la gran revuelta contra Roma [66 al 74 d.C.] y plantean un conjunto de motivos que - salvados aquellos otros que deben inscribirse en el contexto más amplio del panorama económico, social y religioso de la época [s. I d.C.] - , vistos desde la perspectiva del acontecimiento puntual, desvelan algunas de las claves que nos ayudan a comprender tales sucesos. Especialmente, de entre todos los procuradores y por ser el inmediatamente anterior al estallido del conflicto, a Gesio Floro hace responsable de una buena parte del desastre posterior, eso sí, con el aliento de los sectores más extremistas que formaban parte de la facción denominada «cuarta filosofía», integrada por zelotes y sicarios, quienes, para Josefo, fueron partícipes de una guerra brutal, que culminaría con el asedio de Jerusalén y la destrucción del Templo por las legiones de Tito, durante el verano de aquel trágico año del 70 d.C.

\section{ANEXO}

Agripa II (50?-92/93 d.C.)

[Breve biografía]

Marco Julio Agripa (II), hijo de Agripa (I), fue educado en Roma donde se encontraba a la muerte de su padre. El emperador Claudio, aunque tenía la intención de nombrarle sucesor del padre en Judea, finalmente no lo hizo al seguir el criterio de sus consejeros, que veían en él a un muchacho (contaba entonces diecisiete

57 «...las helépolis, las oxibelas y otras muchas máquinas que luego recogieron los judíos y las utilizaron contra los que las habían dejado allí» [F.J. Bell lud., II, 553. Traducción: J. M. ${ }^{a}$ Nieto Ibáñez].

${ }^{58}$ Unas cifras, aún siendo importantes, inferiores a las pérdidas ocasionadas al legado de Augusto, Publio Quintilio Varo por el querusco Arminio en el saltus Teutoburgiensis (9 d.C.), donde dejaron de existir las legiones XVII, XVIII y XIX (legiones nunca repuestas) y sus correspondientes tropas auxiliares. E. Pitillas Salañer, «Tiberio y los germanos», Homenaje al Profesor Montenegro. Estudios de Historia Antigua, Universidad de Valladolid, 1999, 401.

59 B. Niese, Flavii Josephi opera, I-VII, Berlín, 1885-1889. Ed. maior.

60 J. Rodríguez González, Historia de las legiones romanas, I, Madrid, 2001, 325. 
años) inmaduro y pusilánime. En compensación Claudio le otorgó (52 d.C.), a la muerte de su tío Herodes de Calcis, el pequeño reino situado en el Líbano, con el derecho (ya habitual, pues Herodes el Grande y su propio padre habían hecho uso del mismo) a nombrar y deponer sumos sacerdotes. Al año siguiente (53 d.C.) Claudio le concede a cambio del reino de Calcis la tetrarquía de Filipo (Batanea, Traconítide y Gaulanítide), la de Lisanias (Abila) y el territorio de Varo (hijo de Sohemo, tetrarca del Líbano). Por último - y bajo el emperador Nerón- recibe también parte de Perea y de Galilea. En sus estancias en Roma había intercedido para que los judíos conservaran las vestimentas sagradas del sumo sacerdote y para que éstas no quedaran, custodiadas en la Torre Antonia, en manos romanas, como pretendía el procurador Cuspio Fado (¿44?-46 d.C.) [Ant., XX, 10-14]. Abogó también ante Agripina, última esposa de Claudio, en favor de los judíos en el conflicto que éstos mantenían con los samaritanos en tiempos del procurador Ventidio Cumano (ca. 48-52 d.C.) [Ant., XX, 134-136].

Su hermana Berenice (II), viuda de Herodes de Calcis (48 d.C.) y madre de dos hijos, vivió en su casa y corría el rumor, que no llegó a disiparse del todo, que ambos hermanos mantenían relaciones, sospecha que se alimentó al fracasar la boda entre aquella y Polemón de Cilicia [vid., cuadro genealógico: Familia Herodiana]. Así circulaba esta murmuración en Roma (F. Josefo, Ant., XX, 145; Juvenal, Sat., VI, 156-160).

Agripa (II) pudo haber renunciado a la limitada autonomía política de la que disfrutó su padre frente a Roma. El hijo se mostró siempre como una aliado fiel a la potencia hegemónica, si bien las circunstancias cada vez eran menos propicias para veleidades identitarias, ya que a la acción directa de los procuradores romanos (muchas veces inoportuna y zafia) se unía, en el otro extremo, el radicalismo zelote. El soberano cambió el nombre de la capital del reino (Cesarea de Filipo) por el de Neronías, como muestra de marcado servilismo hacia el nuevo purpurado (Nerón). Sus acuñaciones llevaron el nombre de los emperadores reinantes: Nerón, y los integrantes de la dinastía flavia: Vespasiano, Tito y Domiciano. Se le atribuye un carácter débil e indolente. En Jerusalén residió en el antiguo palacio de los asmoneos, edificio situado a una cierta altura y desde donde podía contemplar las ceremonias religiosas de los sacerdotes del Templo. Éstos se sintieron incomodados y decidieron, para evitar la insolencia del monarca, construir un muro que Agripa, aunque se empeñó, no pudo derribar. Aunque recurre al procurador romano de turno (Cuspio Festo) los sacerdotes hacen valer sus derechos en Roma, cuentan con el apoyo explícito de la emperatriz Popea y Agripa debe renunciar a sus impúdicas pretensiones [Ant., XX, 189-196].

Al estallar la revuelta judía (66 d.C.) Agripa se encontraba en Alejandría donde rápidamente se puso al servicio del prefecto de Egipto, Tiberio Julio Alejandro. Agripa y su hermana Berenice (y esto hay que decirlo a favor de ambos) hicieron lo que pudieron para reconducir la rebelión y apaciguar los ánimos. Pero todo fue en vano. Josefo transmite un largo discurso (habría que suponer totalmente construido y en el que perfila su propio pensamiento) en el que Agripa se dirige a su pueblo. En el mismo (Bell lud., II, 345-401) hace un erudito repaso a todos los pueblos dominados por Roma, mucho más poderosos - y con más medios bélicos- que los judíos y que vivían integrados en el mundo romano. Pero, como transmite Jo- 
sefo en los libros de su largo relato (Guerra de los judíos), los acontecimientos desbordaron a los sectores moderados y todo fue inútil. Incluso el propio Josefo (quizá a su pesar) fue aupado a la jefatura de la improvisada milicia en Galilea.

En el asedio de Gamala Agripa fue herido levemente y hacia el año 67 d.C., cuando Vespasiano (futuro purpurado) había ya emprendido la ocupación de buena parte del territorio (norte de Palestina), antes en armas, Agripa volvía a recuperar su reino parcialmente perdido. Cuando acompañaba a Tito (hijo de Vespasiano) a Roma a rendir homenaje a Galba, nuevo emperador, recibe la noticia de su asesinato (15 de enero del año 69). Permanece en Roma, mientras Tito regresa con su padre a la espera de acontecimientos, que se acaban decantando (tras el paréntesis de los efímeros reinados de Otón y Vitelio) por el apoyo que las legiones de Oriente prestan a Vespasiano, siguiente purpurado. Agripa regresa a Palestina llamado por Berenice, su hermana, partidaria desde el comienzo del partido flaviano. A partir de este momento Agripa no se separa de Tito, aporta tropas y participa en el largo asedio de Jerusalén, que concluye con la ocupación de la capital judía (70 d.C.) por tropas romanas y pueblos aliados.

A partir del año 75 d.C. Agripa y su hermana Berenice viven en Roma. Berenice reside en el Palatino ya que mantenía relaciones amorosas con Tito desde tiempo atrás en Palestina. Pero la opinión pública no ve con buenos ojos a la nueva Cleopatra judía. Las presiones fueron en aumento hasta que Tito se vio obligado a despedirla y tras la muerte de su padre Vespasiano (23 de junio del 79 d.C.) decidió ignorarla totalmente (a pesar de que la reina había decidido regresar a Roma desde Judea).

Poco es lo que sabemos de la vida de Agripa (II) y de su hermana Berenice (II) en esta etapa final. Las acuñaciones de Agripa continúan durante el reinado de Domiciano y parece que Marco Julio Agripa (II) pudo fallecer hacia el 92/93 d.C. Al morir sin descendencia sus territorios fueron incorporados a la provincia romana de Siria. Con Agripa (II) terminaba la saga de la familia Herodes, iniciada por Herodes el Grande (40-4 a.C.) hacía más de un siglo [vid., Familia Herodiana].

\section{LA FAMILIA HERODIANA}

Herodes el Grande - Mariamme, princesa asmonea
$[$ [m. 4 a.C.]

Alejandro /Aristóbulo —— Berenice (I) / Salampsió /Cipro (III)

[m. 7 a.C.] [m. 7 a.C.]

Herodes de Calcis * / Agripa (I)—Cipro (II) / Herodías [m. 44 d.C.]

M. Julio Agripa (II) / Berenice (II) — Herodes de Calcis* / Mariamme / Drusila [m. 92/93 d.C.] Polemón de Cilicia 
El origen de la revuelta judía contra Roma (66 d.C.) según el testimonio...

Tabla 1. Provincia romana de Syria. Etapa imperial [30 a.C.-70 d.C.]

\begin{tabular}{|c|c|c|c|c|c|}
\hline N. ${ }^{\circ}$ & Imperator & N..$^{\circ}$ & $\begin{array}{l}\text { Legatus Augusti } \\
\text { pro praetore }\end{array}$ & Cronología & Fuente \\
\hline \multirow{14}{*}{1} & \multirow{14}{*}{$\begin{array}{l}\text { Octaviano/Augusto } \\
\text { [30/27 a.C.-14 d.C.] }\end{array}$} & 1 & Q. Didio & 30 a.c. & $\begin{array}{l}\text { D. Cass., LI, 7. F.J. Ant., } \\
\text { XV, 6, } 7 \text { (195) }\end{array}$ \\
\hline & & 2 & $\begin{array}{l}\text { M. Valerio Mesala } \\
\text { Corvino }\end{array}$ & 29 a.C. & Ap. B.C., IV, 38-162 \\
\hline & & 3 & M. Tulio Cicerón & $\begin{array}{c}\text { ¿29-27?- ¿27-25? } \\
\text { a.C. }\end{array}$ & Ap. B.C. IV, 51-221 \\
\hline & & 4 & $\begin{array}{l}\text { (M. Terencio) } \\
\text { Varrón }\end{array}$ & ¿24-23? a.C. & $\begin{array}{l}\text { F.J. Ant., XV, 10, } 1 \text { (345); } \\
\text { Bell lud., I, 20, } 4 \text { (398) }\end{array}$ \\
\hline & & 5 & $\begin{array}{l}\text { M. Vipsanio } \\
\text { Agripa }\end{array}$ & 23-13 a.C. & $\begin{array}{l}\text { F.J. Ant., XV, 10, 2 (230) } \\
\text { y XVI, 3, } 3 \text { (86) }\end{array}$ \\
\hline & & 6 & M.Titio & Hacia el 10 a.C. & F.J. Ant., XVI, 8, 6 (270) \\
\hline & & 7 & C. Sentio Saturnino & ¿10-9?-7/6 a.C. & F.J. Ant., XVI, 9, 1 (280) \\
\hline & & 8 & P. Quintilio Varo & 7/6-4 a.C. & F.J. Ant., XVII, 5, 2 (89) \\
\hline & & 9 & ¿L. Calpurnio Piso? & hacia 4-1 a.C. & ILS, $918 ?$ \\
\hline & & 10 & ¿P. Sulpicio Quirino? & 4-2 a.C. & $\begin{array}{l}\text { Estrabón, XII, 6, } 5 \text { (567) } \\
\text { Tac. Ann., III, 48. Lc, 2, } 1\end{array}$ \\
\hline & & 11 & ¿G. Julio César? & 1 a.C.- 4 d.C. & Orosio, VII, 3,4 \\
\hline & & 12 & L. Volusio Saturnino & 4-5 d.C. & RE IV, cols. 1857 ss. \\
\hline & & 13 & P. Sulpicio Quirino & 6 d.C. & $\begin{array}{c}\text { CIL III, 6687=ILS, 2683. F.J } \\
\text { Ant., XVII, 13, } 5 \text { (335); XVIII } \\
1,1(1) ; 2,1 \text { (26) }\end{array}$ \\
\hline & & 14 & $\begin{array}{l}\text { Q. Cecilio Metelo } \\
\text { Crético Silano }\end{array}$ & 12-17 d.C. & $\begin{array}{l}\text { F.J. Ant., XVIII, 2, } 4 \text { (52). } \\
\text { Tac. Ann., II, } 4\end{array}$ \\
\hline \multirow{5}{*}{2} & \multirow{5}{*}{$\begin{array}{l}\text { Tiberio [19-VIII-14 } \\
\text { d.C./ 16-III-37 d.C.] }\end{array}$} & 15 & Cn. Calpurnio Pisón & 17-19 d.C. & Tac., Ann., II, 43 \\
\hline & & 16 & C. Sentio Saturnino & 19-21 d.C. & $\begin{array}{l}\text { Tac., Ann., II, 74; CIL III, } \\
\text { 6703= IGLS I, } 164\end{array}$ \\
\hline & & 17 & L. Elio Lamia & hasta el 32 d.C. & Tac., Ann., VI, 27 \\
\hline & & 18 & L. Pomponio Flaco & 32-¿35? d.C. & Tac., Ann., VI, 27 \\
\hline & & 19 & L. Vitelio & 35-39 d.C. & Tac., Ann., VI, 32 \\
\hline 3 & $\begin{array}{l}\text { Calígula [16-III-37 } \\
\text { d.C./ 24-I-41 d.C.] }\end{array}$ & 20 & P. Petronio & ¿39?-41/42 d.C. & $\begin{array}{c}\text { F.J. Ant., XVIII, 8, 2-9 } \\
(261-309)\end{array}$ \\
\hline \multirow{3}{*}{4} & \multirow{3}{*}{$\begin{array}{l}\text { Claudio [24-I-41 } \\
\text { d.C./13-X-54 d.C.] }\end{array}$} & 21 & C. Vibio Marso & 41/42-44/45 d.C. & F.J. Ant., XIX, 6, 4 (316) \\
\hline & & 22 & C. Casio Longino & 44/45-50 d.C. & F.J. Ant., XX, 1, 1 (1) \\
\hline & & 23 & $\begin{array}{l}\text { C. Umidio Durmio } \\
\text { Cuadrato }\end{array}$ & 50-60 d.C. & $\begin{array}{c}\text { Tac., Ann., XII, 45; XIII, 8-9 } \\
\text { XIV, 26; F.J. Ant., XX, 6,2 } \\
\text { (125-133) }\end{array}$ \\
\hline \multirow[b]{3}{*}{5} & \multirow{3}{*}{$\begin{array}{l}\text { Nerón [13-X-54 } \\
\text { d.C./9-VI-68 d.C.] }\end{array}$} & 24 & $\begin{array}{l}\text { Cn. Domicio } \\
\text { Corbulón }\end{array}$ & 60-63 d.C. & \begin{tabular}{|c|} 
Tac., Ann., XIV, 26; XV, 1, \\
1-17; Dión, LXII, 10 ss.
\end{tabular} \\
\hline & & 25 & C. Cestio Galo & ¿63?-66 d.C. & $\begin{array}{c}\text { F.J. Ant., XX, 11, 1 (257); } \\
\text { F.J. Bell. lud., II, 14, } 3 \\
\text { (280); Tac., Hist., V, } 10\end{array}$ \\
\hline & & 26 & C. Licinio Muciano & 64-69 d.C. & \begin{tabular}{|} 
F.J. Bell.Iud., IV, 1,5 (32); 10 \\
5-6 (105-120); [otoño, 69/ \\
apoyo a Vespasiano: F.J. \\
Bell. lud., IV, 11, 1 (632); \\
Tac., Hist., IV, 2, 39; 49; 80, \\
D. Cass., LXV, 22; LXVI, 2
\end{tabular} \\
\hline
\end{tabular}


Tabla 2. Prefectos de Judea (6-41 d.C.)

\begin{tabular}{|c|c|c|c|c|}
\hline $\mathbf{N .}^{\circ}$ & Nombre & Fuente [Flavio Josefo, basic.] & Cronología & Emperador \\
\hline $\mathbf{1}$ & Coponio & $\begin{array}{c}\text { Ant., XVIII, 2, 2 (29-31); } \\
\text { Bello, 8, 1 (117) }\end{array}$ & $6-9$ d.C. & Augusto \\
\hline $\mathbf{2}$ & $\begin{array}{c}\text { Marco Ambíbulo } \\
\text { (Ambíbuco) }\end{array}$ & Ant., XVIII, 2, 2 (31) & $9-12$ d.C. & Augusto \\
\hline $\mathbf{3}$ & Anio Rufo & Ant., XVIII, 2, 2 (32-33) & $12-15$ d.C. & Augusto-Tiberio \\
\hline $\mathbf{4}$ & Valerio Grato & Ant., XVIII, 2, 2, (33) & $15-26$ d.C. & Tiberio \\
\hline $\mathbf{5}$ & Poncio Pilato & $\begin{array}{c}\text { Bello II, 9, 2 (169); Ant., XVIII, 2, } \\
\text { 2 (35); Tac., Ann., XV, 44 }\end{array}$ & $26-36$ d.C. & Tiberio \\
\hline $\mathbf{6}$ & Marcelo [ ${ }^{\star}$ ] & Ant., XVIII, 4, 2, (89) & 36 ó 37 d.C. & Calígula \\
\hline $\mathbf{7}$ & Marulo [*] & Ant., XVIII, 6, 10 (237) & $37-41$ d.C. & Calígula \\
\hline
\end{tabular}

[* ¿Dos prefectos diferentes?]

Agripa I [41-44 d.C.], hijo de Aristóbulo (ejecutado el 7 a.C. por orden de Herodes el Grande) y Berenice: ejerce su autoridad sobre Judea sustituyendo a los prefectos, quienes* habían iniciado su mandato tras la destitución de Arquelao [4 a.C.-6 d.C.], hijo de Herodes el Grande (muerto en el 4 a.C.)

Tabla 3. Procuradores romanos (44-66 d.C.)

\begin{tabular}{|c|c|c|c|c|}
\hline N. $^{\circ}$ & Nombre & Fuente [Flavio Josefo, basic.] & Cronología & Emperador \\
\hline $\mathbf{1}$ & Cuspio Fado & $\begin{array}{r}\text { Bello, II, 11, 6 (220); Ant., XIX, 9, } \\
2(363)\end{array}$ & $44 ?-46$ d.C. & Claudio \\
\hline $\mathbf{2}$ & $\begin{array}{c}\text { Tiberio Julio } \\
\text { Alejandro }\end{array}$ & $\begin{array}{r}\text { Ant., XX, 5, 2 (100); XVIII, 8, } \\
1(259)\end{array}$ & ?-46/48 d.C. & Claudio \\
\hline $\mathbf{3}$ & $\begin{array}{c}\text { Ventidio } \\
\text { Cumano }\end{array}$ & $\begin{array}{c}\text { Bello, II, 12, 1-7 (223-246); Ant., } \\
\text { XX, 5, 2 (103); 5, 3-6, 5 (105- } \\
136) ; \text { Tac., Ann., XII, 54, 3 }\end{array}$ & 48-ca.52 d.C. & Claudio \\
\hline $\mathbf{4}$ & Félix & $\begin{array}{r}\text { Bello, II, 12, 8 (247); Ant., XX, 7, } \\
1(137) ; \text { Suet., Claud., 28 }\end{array}$ & $52-60$ d.C. & Claudio-Nerón \\
\hline $\mathbf{5}$ & Porcio Festo & $\begin{array}{r}\text { Bello, II, 14, 1 (271); Ant., 8, } \\
9(182)\end{array}$ & i-60/62 d.C. & Nerón \\
\hline $\mathbf{6}$ & Albino & Bello, VI, 5, 3 (300-309) & $62-64$ d.C. & Nerón \\
\hline $\mathbf{7}$ & Gesio Floro & $\begin{array}{r}\text { Bello II, 14, 2 (277); Ant., XX, 11, } \\
1(252-253)\end{array}$ & $64-66$ d.C. & Nerón \\
\hline
\end{tabular}

[Judea y Palestina, cuya situación política no difiere entre sí, no fue incorporada a la provincia de Siria donde mandaba un gobernador de rango senatorial (legatus Augusti pro praetore); en Judea el gobernador era de rango ecuestre [praefectus=(rango militar]; desde el emperador Claudio se le denomina procurador (funcionario de hacienda pública), si bien su triple función militar, judicial y financiera (fiscal) fue semejante en ambos casos] [Tablas elaboradas con información extraída de E. Schürer, Historia del pueblo judío en tiempos de Jesús, I, Madrid, 1985, 462 ss y 583 ss]. 